\title{
Effect of adzuki bean sprout fermented milk enriched in Y-aminobutyric acid on mild depression in a mouse model
}

\author{
Zhen Wu, ${ }^{1 *} \odot$ Pengyu Wang, ${ }^{2} \odot$ Daodong Pan, ${ }^{1,2,3 *} \odot$ Xiaoqun Zeng, ${ }^{1}$ Yuxing Guo, ${ }^{2} \odot$ and Guangsheng Zhao ${ }^{4}$ \\ ${ }^{1}$ State Key Laboratory for Managing Biotic and Chemical Threats to the Quality and Safety of Agro-products, Key Laboratory of Animal Protein \\ Deep Processing Technology of Zhejiang, School of Food and Pharmaceutical Sciences, Ningbo University, Ningbo, Zhejiang 315211, P. R. China \\ ${ }^{2}$ School of Food Science \& Pharmaceutical Engineering, Nanjing Normal University, Nanjing 210046, P. R. China \\ ${ }^{3}$ National R\&D Center for Freshwater Fish Processing, Jiangxi Normal University, Nanchang, Jiangxi 330022, P. R. China \\ ${ }^{4}$ Hangzhou New Hope Shuangfeng Dairy Co., Hangzhou, Zhejiang 310000, P. R. China
}

\section{ABSTRACT}

This study focused on the ability of adzuki bean (Vigna angularis) sprout fermented milk, which is rich in $\gamma$-aminobutyric acid (GABA), to relieve anxiety and mild depression. A high-yield GABA-producing strain, Lactobacillus brevis J1, from a healthy cow was screened, and its physiological and probiotic properties were evaluated. The effect of adzuki bean sprout fermented milk was investigated in vivo in a chronic depression mouse model. The results showed that $L b$. brevis J1 had excellent probiotic properties, grew well at low $\mathrm{pH}$ and $3 \% \mathrm{NaCl}$, and adhered to the surface of HT-29 cells. The GABA-enriched $(241.30 \pm 1.62 \mu \mathrm{g} /$ $\mathrm{mL}$ ) adzuki bean sprout fermented milk prepared with Streptococcus thermophilus, Lactobacillus bulgaricus, and Lactobacillus plantarum, and Lb. brevis J1 can reduce and possibly prevent mild depression-like symptoms in mice $(\mathrm{C} 57 / \mathrm{B} 6)$ by increasing social interaction and enhancing the pleasure derived from movement. The research revealed that the $\mathrm{GABA}_{\mathrm{B}}$-cyclic AMP-protein kinase A-cAMP-response element binding protein $\left(\mathrm{GABA}_{\mathrm{B}}\right.$-cAMP-PKA-CREB) signaling pathway was related to the depression-like symptoms and that levels of 5-hydroxytryptamine, norepinephrine, and dopamine in the hippocampus of mice increased after treatment with the adzuki bean sprout fermented milk. Our results suggest that GABA-enriched dairy products have the potential to prevent or treat mild depression-like symptoms in mice, which suggests a new approach for a dietary therapy to treat chronic social stress.

Key words: $\gamma$-aminobutyric acid, Vigna angularis, Lactobacillus brevis, $\gamma$-aminobutyric acid (GABA)enriched fermented milk, mild depression

Received June 24, 2020.

Accepted August 18, 2020.

*Corresponding authors: woodsen163.com and daodongpan@163 .com

\section{INTRODUCTION}

With rapid urbanization in developing countries over the past several decades, mild depression in city dwellers caused by psychological, social, and economic pressures has become a serious and long-term public health problem. Worse, mild depression can lead to persistent depressive disorders, especially in young people (Anakwenze and Zuberi, 2013). Although antidepressant drugs are effective, they are not universally so and can cause strong dependency (Chuang et al., 2011). Therefore, dietary therapy has increasingly been seen by physicians and patients as an alternative approach to the treatment of chronic mild depression (Felton and Cervenka, 2015).

$\gamma$-Aminobutyric acid (GABA) is a common nonprotein amino acid that can act as an inhibitory neurotransmitter to relieve depression (Barrett et al., 2012) while fulfilling several other important physiological functions, such as lowering blood pressure (Alves et al., 2016) and managing diabetes by converting glucagonproducing cells to large numbers of $\beta$-like cells (Weir and Bonner-Weir, 2017). It also has been shown to produce an anti-stress effect in humans (Vaiva et al., 2004) and to lessen the symptoms of depressive disorders (Okada et al., 2000). Recent advances in food and nutrition science have highlighted the possibility of modulating certain specific physiological functions through food intake (Jiménez-Colmenero, 2013), including using functional foods containing a high concentration of GABA to treat chronic mild depression. In general, food-grade GABA is derived from germinated cereals and microorganisms (Diana et al., 2014), such as germinated brown rice and barley (Lin et al., 2015). Lactobacillus strains are also a good source of GABA; lactic acid bacteria such as Lactobacillus brevis and Lactobacillus plantarum can produce high amounts of GABA (Wu et al., 2018). However, these types of basic food sources are not plentiful enough to meet the potential adult demand for food products made with GABA. 
Lactic acid bacteria (LAB) are commonly used as commercial starters to make many fermented foods and beverages; they have many beneficial effects, such as reducing the risk of gastrointestinal diseases (Minervini et al., 2009; Sharifi Yazdi et al., 2017). Different kinds of Lactobacillus found in fermented food have been shown to display GABA-accumulating properties, such as $L b$. paracase $i$ in the fermented fish product funa sushi (Komatsuzaki et al., 2005), Lb. brevis in salt-fermented Jot-gal (cod gut; Lee et al., 2010), Lb. rhamnosus in Nostrano cheese, and Lb. otakiensis in Pico cheese (de los Reyes-Gavilan et al., 2015; Ribeiro et al., 2018). Research has also revealed that Lactobacillus taken orally can increase GABA content in the brain, which helps regulate many physiological and psychological processes (Janik et al., 2016). Oral treatment with Lb. rhamnosus was found to attenuate stress-related disorders in male C57BL/6 mice (Bharwani et al., 2017). Lactobacillus strains possess the ability to produce high levels of GABA, and they can be used as functional starters to manufacture novel fermented dairy foods with beneficial health effects (Sharma and Kanwar, 2017).

Plant-derived foods provide many potential health benefits. The adzuki bean (Vigna angularis) was domesticated in China about 12,000 years ago. Since then, it has been consumed as a common type of bean that is rich in protein and dietary fiber (Oliveira et al., 2017). After germination, some antinutritional factors such as levels of phytic acid and protease inhibitors decrease, and many functional secondary metabolites, such as GABA and soy isoflavones, are formed that provide health benefits to humans (Shi et al., 2010; Fayed, 2015). Okada et al. (2000) first showed that defatted rice germ enriched with GABA can reduce symptoms such as sleeplessness, somnipathy, and depression in patients. Patterson et al. (2019) also demonstrated the positive effect of GABA on metabolism and depressivelike behavior.

Dietary therapy is a good approach to the treatment of chronic illness, and natural compounds and natural approach to food processing are currently popular among consumers (Gahruie et al., 2015). Because both fermented dairy products and germinated adzuki beans produce GABA, we screened LAB strains to identify a high-yield GABA-producing Lactobacillus and prepared adzuki bean sprouts for a fermented milk product with high levels of GABA. A mild depression-like mouse model with C57/B6 male mice was used to explore the possible mechanism by which the GABA-enriched fermented milk affects depression. The novel fermented milk product in this study represents a new approach for using plant-derived components in the development of dairy products for the adjuvant treatment of chronic diseases.

\section{MATERIALS AND METHODS}

\section{Screening of GABA-Producing $L A B$}

Eighty LAB strains were isolated from 20 types of fermented kimchi, 10 samples of gastrointestinal tract contents from healthy fish (Ctenopharyngodon idellus), and 10 samples of fresh milk. The LAB strains were incubated in de Man, Rogosa, and Sharpe (MRS) broth for $24 \mathrm{~h}$ at $37^{\circ} \mathrm{C}$. To identify LAB with high GABA-producing capability, strains were grown in MRS broth containing $1.0 \%$ (wt/vol) monosodium glutamate (MSG) and then the supernatants were centrifuged for detection. The GABA contents were preliminarily identified by thin layer chromatography using butyl alcohol, glacial acetic acid, and water (5:3:2 vol/vol/vol) plus $0.1 \%$ (wt/vol) ninhydrin (Li et al., 2009). After chromatography, the paper was dried at $90^{\circ} \mathrm{C}$ for 10 min and the specific shift value $\left(R_{f}\right)$ was calculated. For the quantification of GABA production in a selected strain, an amino acid analyzer (L-8900, Hitachi, Tokyo, Japan) was used to detect the GABA concentration in the fermented culture media of the screened strains.

The GABA-producing LAB were further identified by fermentation potential tests and $16 \mathrm{~S}$ rDNA analysis (Komatsuzaki et al., 2005). Their fermentation potential on different sugars was determined using an API rapid $\mathrm{CH}$ fermentation strip kit (bioMérieux, Marcy l'Étoile, France). The 16S rDNA sequence analysis procedure was as follows: total DNA of a strain in 1.0 $\mathrm{mL}$ of MRS medium was extracted using a bacterial genomic DNA extraction kit (Takara, Shiga, Japan). The general primers $1492 \mathrm{R}$ and $27 \mathrm{~F}$ were used for amplification. The PCR fragments $(1,500 \mathrm{bp})$ were purified using a quick PCR purification kit (Takara) and sequenced by Sangon Biotech (Shanghai, China). Then, a phylogenetic tree was constructed by generating complete alignment of the 16S rDNA gene of the selected members in GenBank by using MEGA software (https: //www.megasoftware.net/) bootstrap values. Finally, the identified strain was deposited in the China General Microorganisms Collection (CGMCC, Beijing, China) under ID number 15954.

\section{Physiological and Probiotic Properties of Isolated Lb. brevis J1}

The LAB strains were collected and inoculated at $1.0 \%$ in MRS culture medium containing $0.05,0.10$, 0.20 , or $0.30 \%$ (wt/vol) bovine bile salts at $37^{\circ} \mathrm{C}$ for 18 $\mathrm{h}$. The survival rate was calculated based on the value of the viable cells. Gastric and intestinal fluid tolerance tests were carried out as previously described (He et al., 2019). 
The adhesion ability of the collected $L b$. brevis $\mathrm{J} 1$ strain was measured according to the method of Mazzarella et al. (2017) with some modifications. The HT29 cells were cultured at $37^{\circ} \mathrm{C}$ in $5 \% \mathrm{CO}_{2}$ and placed on coverslips $\left(5 \times 10^{5}\right.$ cells per well $)$ in Dulbecco's modified Eagle medium and cocultured with carboxyfluorescein succinimidyl ester (CFSE)-labeled Lb. brevis J1. Cells were then fixed with $4 \%$ (wt/wt) paraformaldehyde for $8 \mathrm{~min}$ at $4^{\circ} \mathrm{C}$ and washed 3 times with PBS. Then cells were incubated with $0.1 \%$ (wt/wt) Triton X-100 for $10 \mathrm{~min}, 4^{\prime}, 6$-diamidino-2-phenylindole (DAPI) for $15 \mathrm{~min}$ and mounted using $50 \%$ glycerol. The signals were visualized using laser scanning confocal microscopy (FV 3000, Olympus, Tokyo, Japan).

\section{Fermented Milk with Sprouted Adzuki Beans}

During the milk fermentation, adzuki bean sprout refiner (20\% wt/vol) and MSG $(1.0 \% \mathrm{wt} / \mathrm{vol})$ were added to fresh milk and sterilized at $121^{\circ} \mathrm{C}$ for $5 \mathrm{~min}$. Then, Lactobacillus bulgaricus, Streptococcus thermophilus, and Lactobacillus plantarum 15953 (strain CGMCC15953, which can transfer soybean isoflavones to soybean isoflavone aglycone) and strain $L b$. brevis J1 were combined in a ratio of $1: 1: 3: 1$ to make the GABA-enriched fermented milk at $40^{\circ} \mathrm{C}$. Milk fermented without adzuki bean sprouts or $L b$. brevis J1 was used as the negative control. The $\mathrm{pH}$ of each fermented milk sample was measured using a $\mathrm{pH}$ meter (Ins mark IS128C, Shanghai, China). The adzuki bean sprouts were prepared as follows: adzuki beans were soaked in water at $30^{\circ} \mathrm{C}$ for $6 \mathrm{~h}$ until the moisture content was about $30 \%$ (wt/wt). Then, bean samples $(\sim 200 \mathrm{~g}$ each) were placed in germination trays in a controlledgrowth chamber. Germination proceeded at $25^{\circ} \mathrm{C}$ and pure water was sprayed on the sprouts by an ultrasonic humidifier every $4 \mathrm{~h}$. The sprouted adzuki beans were removed from the germination chamber after $84 \mathrm{~h}$ and collected for milk fermentation.

\section{Water-Holding Capacity and GABA Content of the Adzuki Bean Sprout Fermented Milk}

The water-holding capacity (WHC) was measured as described by Sodini et al. (2005). A homogenized sample of $10 \mathrm{~g}$ of fermented milk (Y) was centrifuged at $4,000 \times g$ for $10 \mathrm{~min}$ at $4^{\circ} \mathrm{C}$, and the whey supernatant from the sample was removed and weighed (WE). The WHC was calculated as follows: WHC $(\%)=[(\mathrm{Y}-$ $\mathrm{WE}) / \mathrm{Y}] \times 100$.

The GABA content was determined using an amino acid analyzer (Hitachi L-8900) as previously described. 3,5-Disulfosalicylic acid was added to the fermented milk $(1: 1, \mathrm{vol} / \mathrm{vol})$ to remove protein and centrifuged at $10,000 \times g$ for $10 \mathrm{~min}$ at $4^{\circ} \mathrm{C}$. The supernatant was filtered through a $0.22-\mu \mathrm{m}$ syringe filter and detected using the analyzer.

\section{Animals, Grouping, and Mouse Model Design}

Five-week-old C57/B6 male mice (around 20 g) were purchased from the Shanghai Xipuer-Bikai Laboratory Animal Co. [SCXK(Hu) 2018-0006; Shanghai, China], and kept in the animal room at $22 \pm 1^{\circ} \mathrm{C}$ under standard housing conditions of a 12:12 $\mathrm{h}$ light/dark cycle for $7 \mathrm{~d}$ before the experiment. All animal experiments carried out in accordance with the UK Animals (Scientific Procedures) Act of 1986 and associated guidelines. For the mild depression-like mouse model design, the GABA dosage $(3.43 \mathrm{mg} / \mathrm{kg})$ was determined according to a previous study (Okada et al., 2000). Fluoxetine, a common antidepressant, was used as a positive control at a dose of $20 \mathrm{mg} / \mathrm{kg}$ of $\mathrm{BW}$ for each mouse. The GABA concentration in the adzuki bean sprout fermented milk was $241.3 \pm 1.62 \mu \mathrm{g} / \mathrm{mL}$, and that in normal fermented milk was $3.67 \pm 0.42 \mu \mathrm{g} / \mathrm{mL}$ in the mice experiment.

All mice were weighed and randomly assigned to 7 groups of 12 mice each: (1) healthy mice administered $0.4 \mathrm{~mL}$ of saline per day $(0.9 \% \mathrm{NaCl}$, control); (2) mild depression-like mouse model, with mice administered $0.4 \mathrm{~mL}$ of saline per day (model); (3) mice administered common fermented milk (normal, $0.4 \mathrm{~mL}$ of fermented milk without GABA per day); (4) mice administered full dose of adzuki bean sprout fermented milk (high, $0.4 \mathrm{~mL}$ of GABA-enriched fermented milk sample per day); (5) mice administered half dose of adzuki bean sprout fermented milk (medium, $0.2 \mathrm{~mL}$ of GABAenriched fermented milk with $0.2 \mathrm{~mL}$ of saline water sample per day); (6) mice administered a low dose of adzuki bean sprout fermented milk (low, $0.1 \mathrm{~mL}$ of GABA-enriched fermented milk with $0.3 \mathrm{~mL}$ of saline water sample per day); and (7) fluoxetine-treated mice (20 mg/kg of BW per day).

After grouping, mice were exposed to social frustration stress for $10 \mathrm{~d}$ to induce mild depressive symptoms. The procedure was as follows: CD1 mice were screened for strong attack ability and then C57/B6 mice were placed as invaders in a large white cage housing the CD1 mice. Each cage contained one CD1 mouse and one C57/B6 mouse. The mice were allowed physical contact for $10 \mathrm{~min} / \mathrm{d}$ and then the C57/B6 and CD1 mice were separated by a small transparent plate for the rest of the day. The plate allowed the C57/B6 mouse to see the CD1 mouse; even though it could not be attacked, the sight would still cause psychological 
stress. The C57/B6 mice were exposed to different CD1 mice every day, and the social interaction experiments were conducted over $10 \mathrm{~d}$.

\section{Depressive-Like Behavior Analysis}

Sucrose Preference Test. The sucrose preference test is a classic method to evaluate the pleasure index of mice (Su et al., 2017). The test was carried out according to Liu et al. (2015) with slight modifications. Before the test, $1.0 \%$ (wt/vol) sucrose in water was given to the test mice for $24 \mathrm{~h}$. After acclimation, the mice were weighed, placed singly in cages, and made to fast for $24 \mathrm{~h}$. Then, each mouse was given a bottle of $1.0 \%$ (wt/vol) sucrose water and a bottle of tap water. After $12 \mathrm{~h}$, the positions of the sucrose and tap water were exchanged and the mice were fed for another 12 h. Finally, the remaining sucrose and tap water were collected and weighed for the sucrose preference test analysis.

Social Interaction. The social ability of mice was evaluated using a social interaction experiment according to the methods of Kaidanovich-Beilin et al. (2011), with some modifications; specifically, the empty chamber was replaced by a mineral water bottle. The mice were placed in a 3 -cabin metal cage for $30 \mathrm{~min}$ to adapt to the environment, and the contact area was set at 3 to $5 \mathrm{~cm}^{2}$ around the cage. Then, 1 mineral water bottle was placed on one side of the whole cabin and the door connecting the other 2 compartments was opened. The time it took for the mouse to reach the mineral water bottle within 2.5 min was recorded. The mineral water bottle was replaced with the same kind of CD1 mouse, and communication times between the same kinds of mice were recorded. The ratio of the 2 recorded times was calculated as the social interaction rate.

Forced Swimming Test. The forced swimming test is also known as the despair experiment. It was performed according to the method described by Smith et al. (2019) and others. Each mouse was individually forced into an open cylindrical container $(10 \times 25 \mathrm{~cm})$. The container contained $15 \mathrm{~cm}$ of water at a constant temperature of $25 \pm 1^{\circ} \mathrm{C}$. The experiment lasted $6 \mathrm{~min}$ and the first 2 min was considered the acclimation period. The period when the mouse floated motionless in the water and only kept their nose above the water was considered immobilization, and the cumulative time of mouse immobility during the 4 min after the acclimation period was measured.

Tail Suspension Test. The tail suspension test was determined according to the method of Xu et al. (2016), with slight modifications. The mice were inverted and attached to a hanging hook with tape at a distance of about $1 \mathrm{~cm}$ from the tip of the tail. Mice were then placed in a universal sound-proof behavior box and hung upside down with their heads $20 \mathrm{~cm}$ from the bottom of the box. The mice struggled to overcome the abnormal posture, but the activity appeared intermittently with signs of despair. A mouse-tail suspension video analysis system recorded each mouse's activity over $6 \mathrm{~min}$. The first $2 \mathrm{~min}$ was considered the adaptation period, and the accumulated time of the mouse's immobility during the subsequent 4 min was then measured.

\section{Quantification of Monoamines}

Before euthanasia, mice were weighed and injected with $5 \mathrm{mg} / \mathrm{kg}$ carprofen (Rimadyl, Pfizer, New York, $\mathrm{NY}$ ) as an analgesic. Then, mice were anesthetized (isoflurane 2-3\% mixed with $30 \% \mathrm{O}_{2}$ and $70 \% \mathrm{~N}_{2} \mathrm{O}$ ) and immediately killed by decapitation; tissues were stored at $-80^{\circ} \mathrm{C}$. Concentrations of 5-hydroxytryptamine (5HT), norepinephrine (NE), dopamine (DA), and cyclic AMP (cAMP) were measured by ELISA kits (ZCI BIO, Shanghai, China) according to the manufacturer's instructions.

\section{Western Blotting}

The samples were centrifuged at $12,000 \times g$ for 30 min at $4^{\circ} \mathrm{C}$. The total protein concentration of the supernatant was determined using a bicinchoninic acid (BCA) protein assay kit (Nanjing Jiancheng Biological Co., Nanjing, China) according to the manufacturer's instructions. After heating at $100^{\circ} \mathrm{C}$ for $5 \mathrm{~min}$, the proteins were separated on SDS-PAGE gels and transferred to polyvinylidene difluoride membranes for immune blotting. The membrane was then blocked with blocking solution ( $5 \%$ skim milk) at room temperature for $2 \mathrm{~h}$ followed by an overnight incubation at $4^{\circ} \mathrm{C}$ with antibodies against GABA B receptor $\left(\mathbf{G A B A}_{\mathrm{B}}\right)$, protein kinase A (PKA), cAMP-response element binding protein (CREB), and phosphorylated (p)-CREB. Horseradish peroxidase-conjugated goat anti-rabbit $\operatorname{IgG}\left(\mathrm{H}^{+} \mathrm{L}\right)$ was used as the secondary antibody. After washing in PBS, the membranes were incubated with secondary antibodies (1:5,000 dilution, Cell Signaling Technology, Danvers, MA), followed by washings 3 times with Tris-buffered saline-Tween. Immunoreactivity was detected with an enhanced chemiluminescence detection system and visualized in an imaging system. $\beta$-Tubulin (1:1,000; Cell Signaling Technology) was used as control. The images were quantified using Image-Pro Plus software (Media Cybernetics, Rockville, MD). 
A

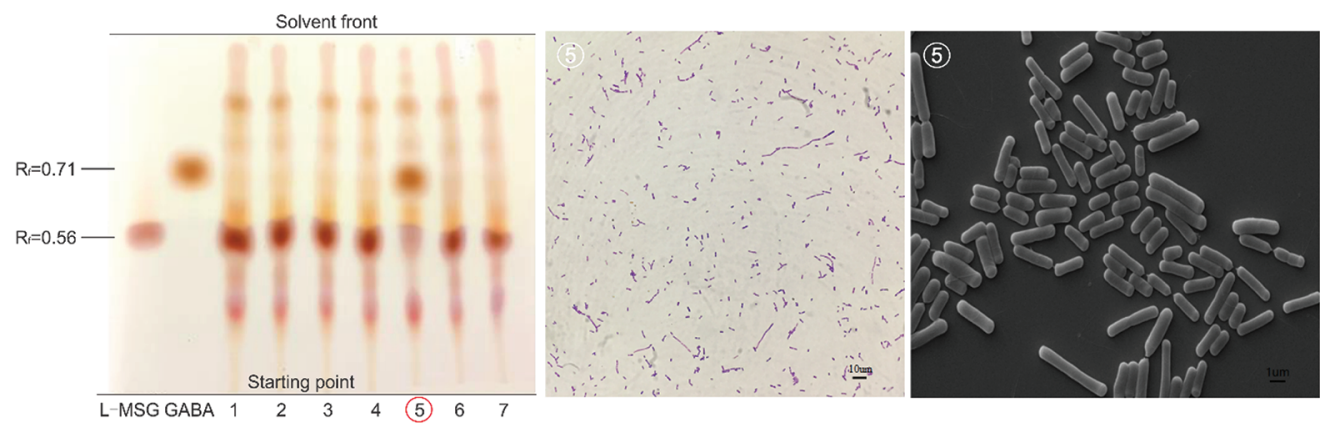

B

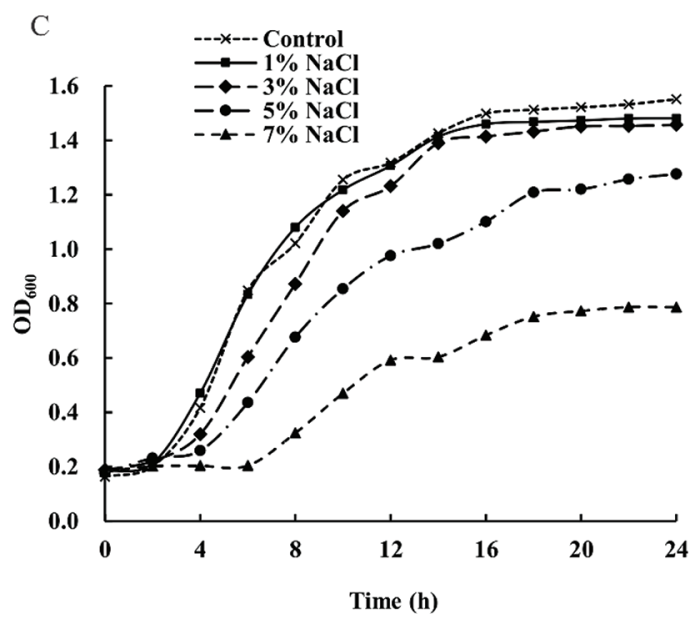

Figure 1. $\gamma$-Aminobutyric acid (GABA)-producing ability (A) and growth characteristics (optical density, OD, at 600 nm) of Lactobacillus brevis $\mathrm{J} 1$ grown in medium with monosodium glutamate (MSG) at different $\mathrm{pH}$ values (B; 3.0, 4.0. 5.0, and 5.8) and $\mathrm{NaCl}$ concentrations (C; $1,3,5$, and $7 \%$ ). (A) Seven screened lactic acid bacteria strains identified by thin layer chromatography; $\mathrm{R}_{\mathrm{f}}=$ specific shift value. Lane 5 shows high GABA production of $L b$. brevis J1; the micrographs show morphology of screened strain number 5 (Lb. brevis J1). (B, C) Effect of different initial de Man, Rogosa, and Sharpe (MRS) pH (B) and concentrations of $\mathrm{NaCl}$ (C) on Lb. brevis J1 growth.

\section{Statistical Analysis}

Experimental data were analyzed using GraphPad Prism 7.0 (GraphPad Inc., San Diego, CA), and analysis of significant differences was performed by one-way ANOVA $(P<0.05)$. Data are expressed as means \pm standard deviations. All experiments were repeated 3 times.

\section{RESULTS}

\section{Isolation, Identification, and Preservation of GABA-Producing $L A B$}

Lactic acid bacteria strains that could convert MSG to GABA were screened and identified using thin layer chromatography and $16 \mathrm{~S}$ rDNA analysis. Among them, strain 5 (Lb. brevis J1) derived from the fresh tract contents of a cow displayed high GABA production of $9.87 \pm 0.18 \mathrm{~g} / \mathrm{L}$ (Figure 1A). The Lb. brevis J1 strain had $99 \%$ similarity to Lactobacillus brevis ATCC14869.
The 16S rDNA sequence was submitted to the National Center of Biotechnology Information with accession number MH266120. The strains with the best physiological properties and carbon source fermentation ability (Lb. brevis J1; Table 1) were used for further study.

\section{Physiological Characteristics and Probiotic Properties of Isolated Strains}

The target strain was cultured in MRS medium with different initial $\mathrm{pH}$ values and concentrations of $\mathrm{NaCl}$ for $24 \mathrm{~h}$ at $37^{\circ} \mathrm{C}$. As shown in Figure 1B, at $\mathrm{pH} 3.0$, the growth of $L b$. brevis J1 was significantly inhibited. Optimal growth was achieved at $\mathrm{pH} 5.0$. At $\mathrm{pH}$ 5.0, Lb. brevis J1 showed high glutamic acid decarboxylase activity. As shown in Figure 1C, Lb. brevis J1 grew well when the $\mathrm{NaCl}$ concentration was $<5 \%$ but grew very little when it was $>7 \%$. The tolerance of Lactobacillus to bile salts is an important factor that determines whether they can reach and colonize the intestinal tract. 
The results in Figure 2A show that the survival rate of $L b$. brevis $\mathrm{J} 1(>55 \%)$ was higher under conditions of $<0.2 \%$ (wt/vol) bovine bile salt, decreasing significantly to $37 \%$ at $0.3 \%$ bovine bile salt $(P<0.05)$. For the stimulated gastric and intestinal juice experiment, the survival rate of $L b$. brevis J1 was significantly decreased in gastric and intestinal juice when the culture time was extended from 2 to $4 \mathrm{~h}(P<0.05)$, although the survival rate was still $>50 \%$ after $4 \mathrm{~h}$ (Figure $2 \mathrm{~B}$ ). Lactobacillus brevis J1 displayed good adhesion abil-

Table 1. Carbon source assimilation (positive or negative) of strain Lactobacillus brevis J1

\begin{tabular}{|c|c|}
\hline Carbohydrate $^{1}$ & Result \\
\hline Glycerol & - \\
\hline Inositol & - \\
\hline Inulin & + \\
\hline D-Arabinose & - \\
\hline Sorbitol & - \\
\hline Raffinose & - \\
\hline D-Ribose & + \\
\hline$\alpha$-Methyl-D-glucoside & - \\
\hline Glycogen & - \\
\hline L-xylose & - \\
\hline Amygdalin & - \\
\hline Gentiobiose & + \\
\hline$\beta$-Methyl-D-xyloside & - \\
\hline Esculin & + \\
\hline D-Lyxose & - \\
\hline D-Glucose & + \\
\hline Cellobiose & - \\
\hline D-Fucose & - \\
\hline D-Mannose & - \\
\hline Lactose & - \\
\hline D-Arabitol & - \\
\hline L-rhamnose & - \\
\hline Sucrose & + \\
\hline Gluconate & + \\
\hline Erythritol & - \\
\hline Mannitol & - \\
\hline Melezitose & + \\
\hline L-Arabinose & + \\
\hline$\alpha$-Methyl-D-mannoside & - \\
\hline Starch & - \\
\hline D-Xylose & + \\
\hline$N$-Acetyl-glucosamine & + \\
\hline Xylitol & - \\
\hline Adonitol & - \\
\hline Arbutin & - \\
\hline D-Turanose & - \\
\hline D-Galactose & - \\
\hline Salicin & + \\
\hline D-Tagatose & - \\
\hline D-Fructose & + \\
\hline Maltose & + \\
\hline L-Fucose & - \\
\hline L-Sorbose & - \\
\hline Melibiose & - \\
\hline L-Arabitol & - \\
\hline Dolcitol & - \\
\hline Trehalose & + \\
\hline 2-Keto-gluconate & - \\
\hline
\end{tabular}

${ }^{1}$ Carbohydrate adoption relays on the API 50CH system (bioMérieux, Marcy l'Étoile, France). ity in the HT-29 cell model as shown by fluorescence microscopy (Figure 2C). With different ratios of $L b$. brevis J1 in fermented milk, the GABA content differed: the ratio of $L b$. bulgaricus: Strep. thermophilus: Lb. plantarum 15953: Lb. brevis $\mathrm{J} 1=1: 1: 3: 1$ (group C in Supplemental Figure S1; https://doi.org/10.3168/jds .2020-19154) had the highest GABA content of 241.3 $\pm 1.62 \mu \mathrm{g} / \mathrm{mL}$, whereas the GABA content in the $L b$. brevis J1-free group (group D in Supplemental Figure S1) was much lower $(P<0.05)$, with a concentration of $215.2 \pm 1.31 \mu \mathrm{g} / \mathrm{mL}$ (Supplemental Figure S1).

\section{Properties of Adzuki Bean Sprout Fermented Milk}

The $\mathrm{pH}$ and viable cell count of the control fermented milk and adzuki bean sprout fermented milk were measured during fermentation. As shown in Figure 3A, at $8 \mathrm{~h}$, the $\mathrm{pH}$ of adzuki bean sprout fermented milk and control fermented milk both decreased below 4.6. The rate of viable bacteria in the GABA-enriched adzuki bean sprout fermented milk was higher than that in the normal fermented milk, which could help shorten the fermentation time (Figure 3B).

\section{Effect of GABA-Enriched Adzuki Bean Sprout Fermented Milk on the Depression-Like Mouse Model}

As shown in Figure $4 \mathrm{~A}-\mathrm{C}$, the sucrose water preference of the control group was significantly higher $(P<0.05)$ than that of the model group, indicating that the depression-like mice model was successfully induced. Compared with the model group, the sucrose water preference of the mice in the adzuki bean sprout fermented milk group was increased in all of the treated groups $(P<0.05)$. We also observed a significant improvement in the social interaction of the mice $(P<$ $0.05)$, especially in the medium- and high-dose groups $(P<0.05)$. Compared with the positive control group, the high-dose group displayed a better response group in facing fear during the forced-swimming and tailsuspension experiments $(P<0.05$; Figure $4 \mathrm{D}, \mathrm{E})$.

\section{Monoamine Transmitter Content in Mouse Hippocampus}

To date, most antidepressants have been shown to work by increasing levels of the monoamine transmitters 5-HT (serotonin), NE, and DA (Yi et al., 2008). To investigate whether GABA-enriched adzuki bean sprout fermented milk similarly affected these neurotransmitters to alleviate symptoms of depression, we analyzed their concentrations in hippocampus tissue of 7 groups 
A

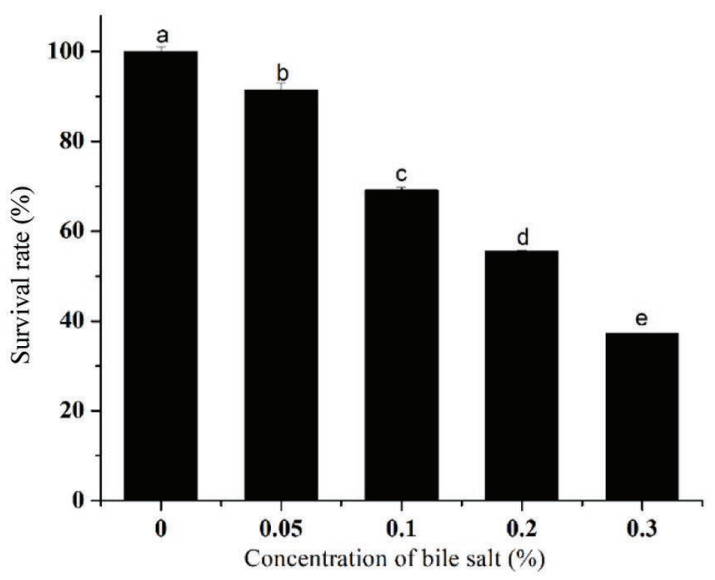

B

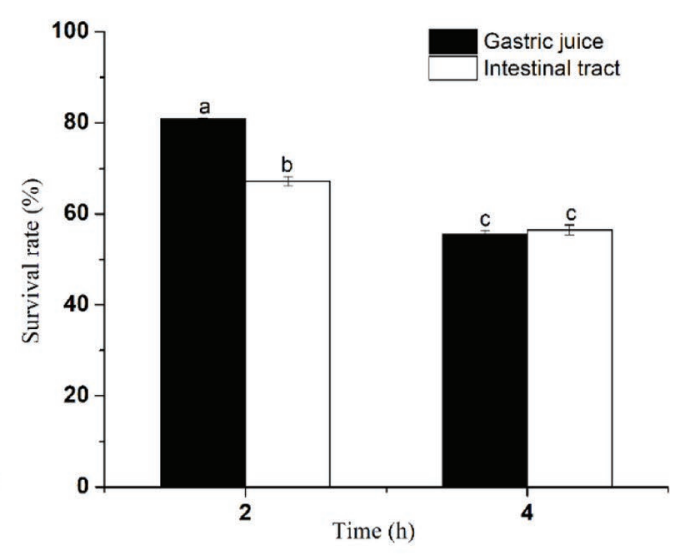

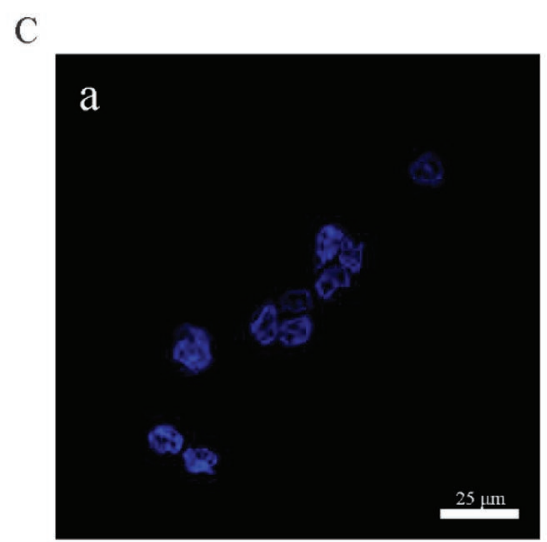
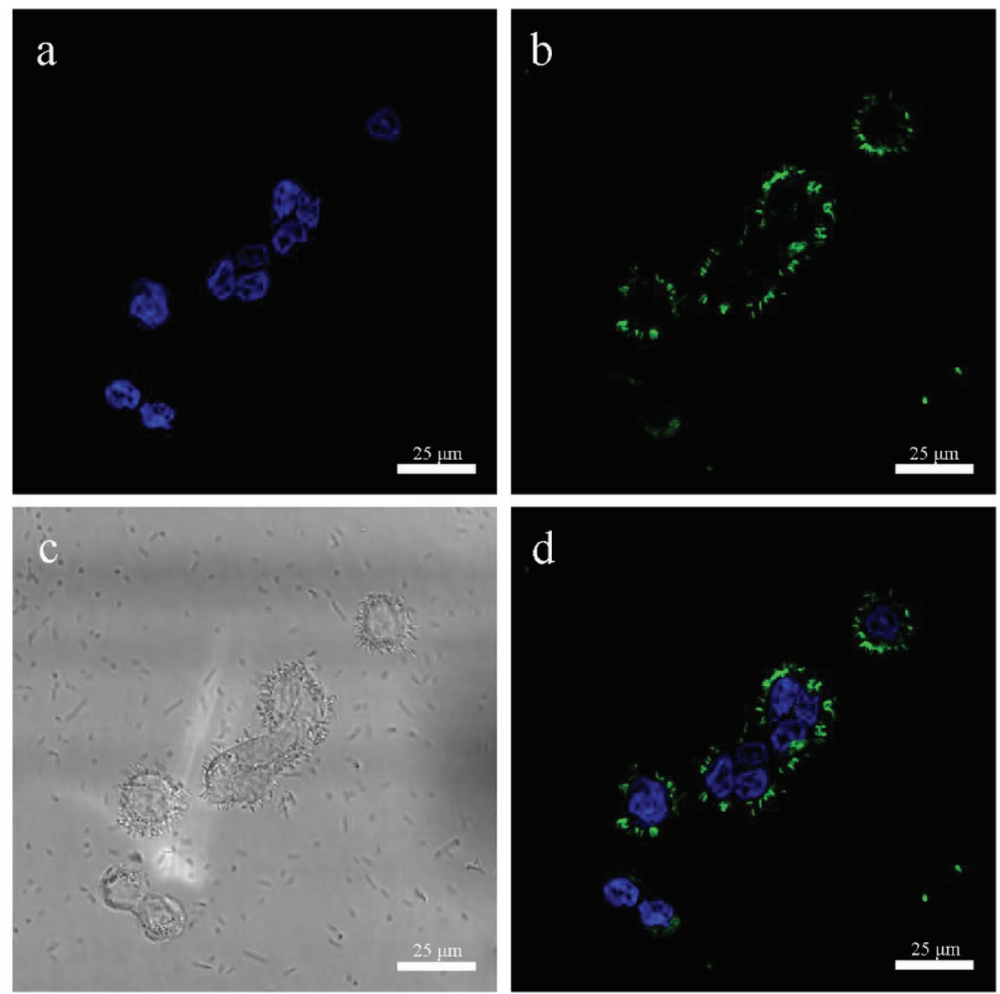

Figure 2. Probiotic properties of isolated Lactobacillus brevis J1. Effects of different concentrations of bile salts (A) and simulated gastrointestinal fluid environment (B) in vitro on Lb. brevis J1 growth. (C) Images of Lb. brevis J1 adhesion in HT-29 cells with confocal laser scanning microscopy. Lactobacillus brevis J1 labeled with carboxyfluorescein succinimidyl ester (CFSE, Figure 2C-b), and HT-29 cells labeled with 4',6-diamidino-2-phenylindole (DAPI, Figure 2C-a). Figure 2C-c is the differential interference contrast image, and Figure 2C-d is the merged images of Figure $2 \mathrm{C}$-a and Figure $2 \mathrm{C}$-b. The different letters $(\mathrm{a}-\mathrm{e})$ in panels $\mathrm{A}$ and $\mathrm{B}$ indicate significant differences between groups $(P<0.05)$; error bars indicate the standard deviation.

of mice. As shown in Figure 5A-C, compared with the blank control group, the concentrations of 5-HT, NE, and DA in the model group of depressed mice were significantly reduced $(P<0.05)$. Mice in the medium- and high-dose groups showed significantly increased levels of 5 -HT and NE $(P<0.05)$, whereas mice in the medium-dose group had significantly increased levels of DA $(P<0.05)$. 


\section{Protein Expression of GABA $A_{B}-C A M P-P K A-C R E B$ Pathway in Mouse Hippocampus}

The cascade response process of $\mathrm{GABA}_{\mathrm{B}}$ receptor activation, second messenger cAMP, PKA activation, CREB phosphorylation, gene transcription regulation, and the subsequent biological effects play an important role in mood regulation. As shown in Figure 6, compared with the blank control group, $\mathrm{GABA}_{\mathrm{B}}$ expression in the model group was significantly decreased $(P<$ 0.05 ), indicating that the depression-like symptoms correlated with the inhibition of $\mathrm{GABA}_{\mathrm{B}}$ expression in the hippocampus. The GABA-fortified fermented milk group showed an increase in $\mathrm{GABA}_{\mathrm{B}}$ expression in a dose-response manner. However, only the high-dose GABA-enriched adzuki bean sprout fermented milk group showed significantly increased cAMP content in the hippocampus (Figure 5D). For PKA and p-CREB, the medium- and high-dose GABA-enriched fermented milk groups showed significantly increased levels $(P<$ $0.05)$.

\section{DISCUSSION}

Increasing evidence suggests that GABA dysfunction plays a major role in depressive disorders and that enhanced levels of GABA neurotransmitters in nerve cells can dramatically improve the response to chronic social-frustration stress (Diana et al., 2014). In this research, we explored the therapeutic potential of GABA-producing germinated adzuki beans and highyield GABA-producing Lb. brevis J1. We developed a GABA-enriched adzuki bean sprout fermented milk product, which was used to make a novel fermented milk with traditional Chinese food elements and key functional properties.

The digestive time of food in the stomach is usually between 2 and $4 \mathrm{~h}$. Human gastric juice is a strong, food-dissolving, complex acidic solution, which can hydrolyze microorganisms in the gastric environment (Nardone and Compare, 2015). Bile salt stress in the gastric tract can damage cell viability by disrupting the cell membrane and cell wall components. Therefore, measuring the tolerance of Lactobacillus to gastric and intestinal juice helps confirm the probiotic effect of Lactobacillus in the gastrointestinal tract. In this study, we showed that $L b$. brevis $\mathrm{J} 1$ has good physiological and probiotic characteristics and can tolerate high concentrations of bile salt $(0.3 \%)$ with a survival rate $>50 \%$ and has good adhesion ability to HT-29. Furthermore, during the milk fermentation process, the adzuki bean sprout fermented milk displayed a larger number of viable bacteria and a higher acidity rate compared with the control fermented milk.

Yogurt has a 3-dimensional network gel structure formed by the accumulation of denatured casein particles. Fat globules and Lactobacillus strains are embedded in this gel fiber network (Berrazaga et al., 2019). This complex structure enhances the WHC of fermented milk. The adzuki bean sprout fermented milk had a more uniform and denser milk gel structure and its WHC was slightly higher fermented milk without adzuki bean sprout. Because of the dietary fiber components in the bean sprouts, a more solid network structure was formed, which can preserve and retain water, and thereby improve the WHC of fermented
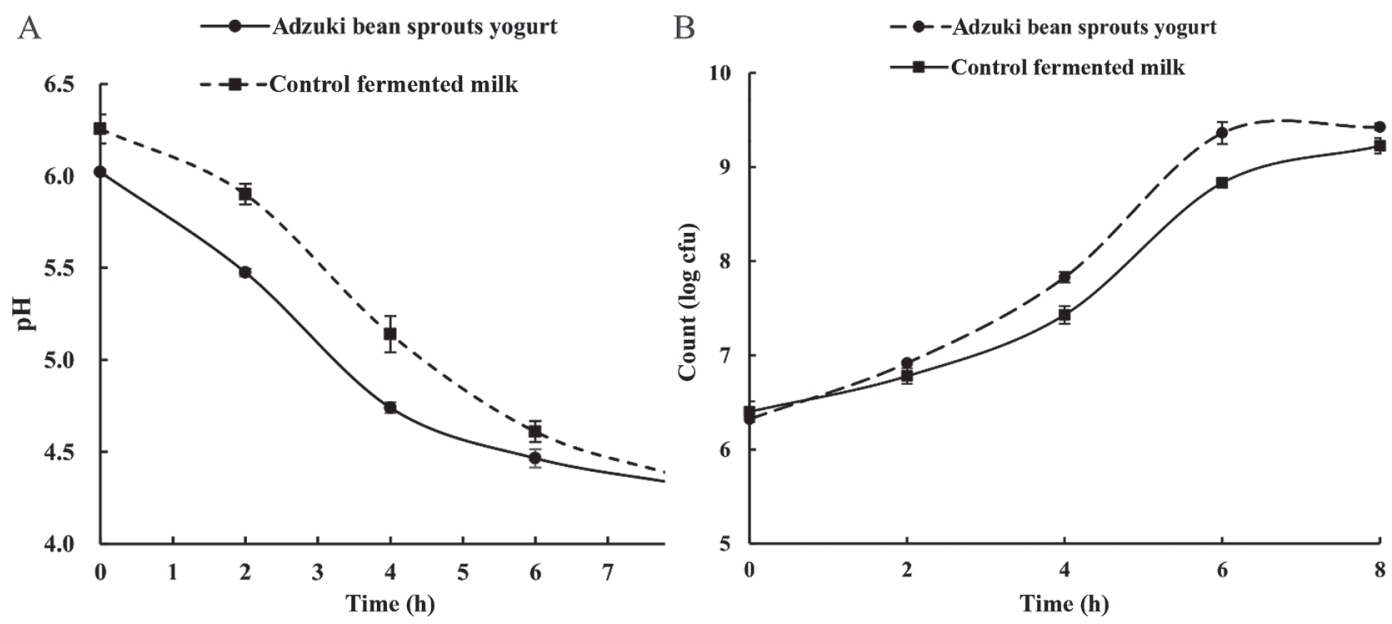

Figure 3. Properties of milk fermented with sprouted adzuki bean. (A) Changes in pH during milk fermentation between the control and adzuki bean sprout fermented milk; (B) changes in growth (log cfu) during milk fermentation. The error bars indicate the standard deviation. 
milk. In addition, a variety of nutritional factors such as fatty acids, free amino acids, and GABA in the adzuki bean sprouts encourage the growth of Lb. brevis $\mathrm{J} 1$ ( $\mathrm{Li}$ et al., 2011), which is why the colony counts of strains were much higher in the adzuki bean sprout fermented milk than in conventional fermented milk.
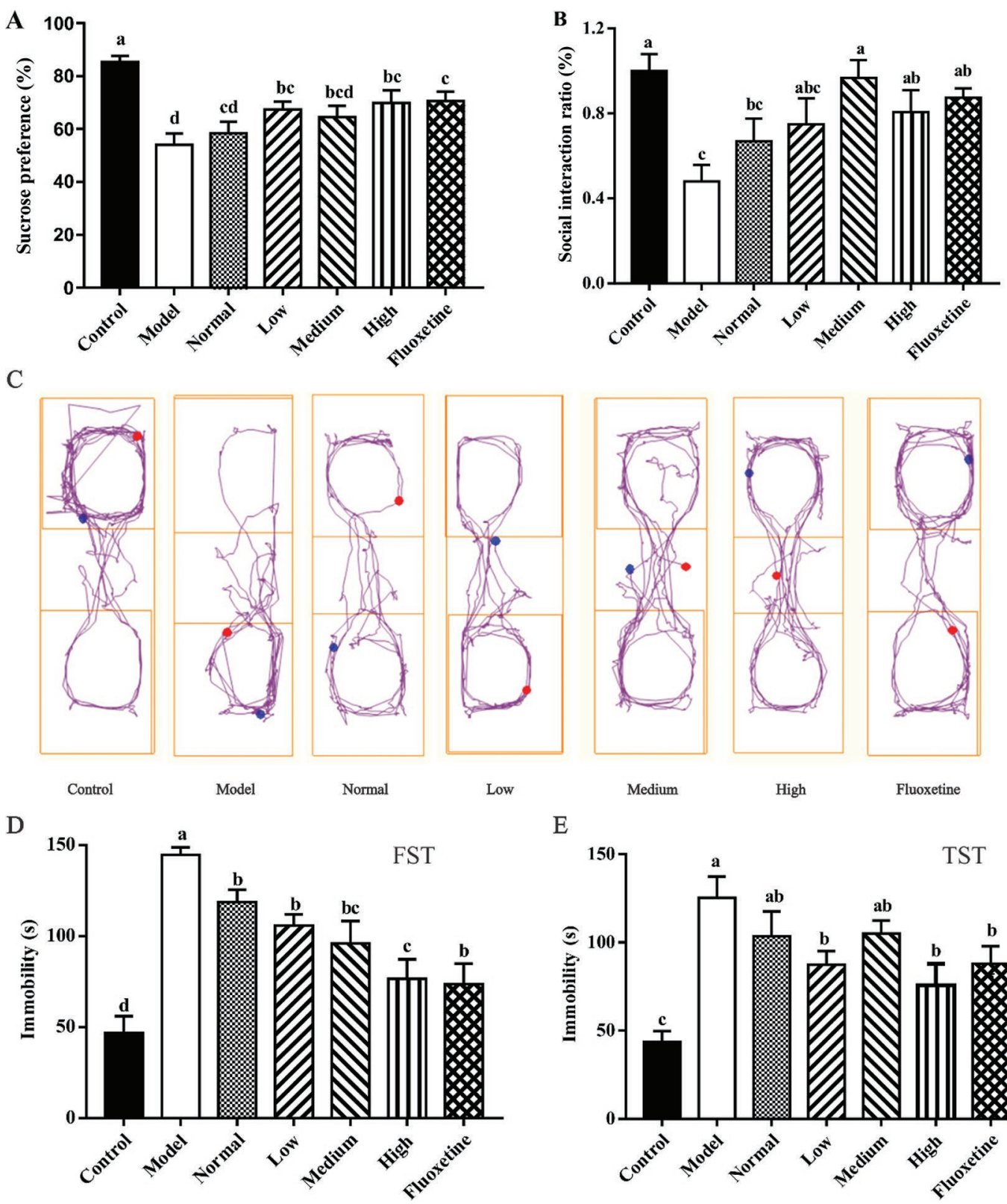

E

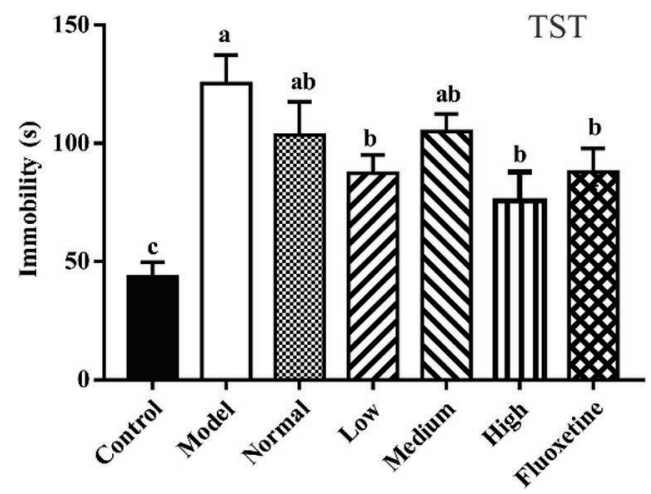

Figure 4. Effect of $\gamma$-aminobutyric acid (GABA)-enriched adzuki bean sprout fermented milk on the depression-like mouse model. (A) Sucrose preference test of mice after different doses of adzuki bean sprout fermented milk; (B) social interaction analysis of different adzuki bean sprout fermented milk-treated mice groups; (C) trajectory maps of mice (dots) in different adzuki bean sprout fermented milk groups; (D) immobility (time spent immobile, s) of mice in the forced-swim test (FST); and (E) immobility of mice in the tail-suspension test (TST) Groups: (1) healthy mice administered $0.4 \mathrm{~mL}$ of saline $(0.9 \% \mathrm{NaCl}$, "control"); (2) mild depression-like mouse model, with mice administered $0.4 \mathrm{~mL}$ of saline (0.9\% NaCl, "model"); (3) mice administered common fermented milk ("normal," $0.4 \mathrm{~mL}$ of fermented milk without GABA); (4) mice administered a low dose of adzuki bean sprout fermented milk ("low," $0.1 \mathrm{~mL}$ of GABA-enriched fermented milk with $0.3 \mathrm{~mL}$ of saline water sample per day); (5) mice administered half dose of adzuki bean sprout fermented milk ("medium," 0.2 mL of GABA-enriched fermented milk with $0.2 \mathrm{~mL}$ of saline per day); (6) mice administered full dose of adzuki bean sprout fermented milk ("high," $0.4 \mathrm{~mL}$ of GABA-enriched fermented milk sample per day); and (7) mice treated with fluoxetine (20 mg/kg of BW per day; "fluoxetine"). The dots in the rectangle represent the test mice; the 3 sections indicate the cabins for communication of the test mice. Different letters (a-d) indicate significant differences between groups $(P<0.05)$, and error bars indicate SD. 
We studied the effects of the adzuki bean sprout fermented milk in a depression-like mouse model. In general, mice will actively make tentative contact with strange mice out of curiosity, but if mice are exposed to chronic social frustration stress, they will evade and not make contact with the strange mice (Nikoui et al., 2016). When mice were treated with the GABA-enriched adzuki bean sprout fermented milk, they showed a significantly higher index of sugar water preference and higher rates of social interaction and swimming immobility than mice in the control group. The trajectory maps of all of the fermented milk groups were more uniform and regular than those for the model group. These data indicate that the GABA-enriched adzuki bean sprout fermented milk can effectively relieve mild depression-like symptoms in a mouse model. Chronic mild stress impairs GABA release and uptake in the medial prefrontal cortex, leading to the lowered GABA levels found in major depression (Ma et al., 2016). Through the facilitated GABA transporter system, GABA can enter and exit the brain. Researchers have found that participants receiving a GABA-fortified beverage had less psychological fatigue after completion of a task than participants who did not receive the GABA supplement (Kanehira et al., 2011).

Neurotransmitters have predominated in the study of the pathogenesis of depression for more than $50 \mathrm{yr}$. It is generally accepted that one or more deficiencies in monoamine transmitters explain the physiopathology of depression (Bunney and Davis, 1965). Studies have shown that GABA administration can affect the levels of monoamine transmitters in the hippocampus (Petty, 1995). Serotonin (5-HT) is a critical monoamine neurotransmitter in the brain. Many studies have shown
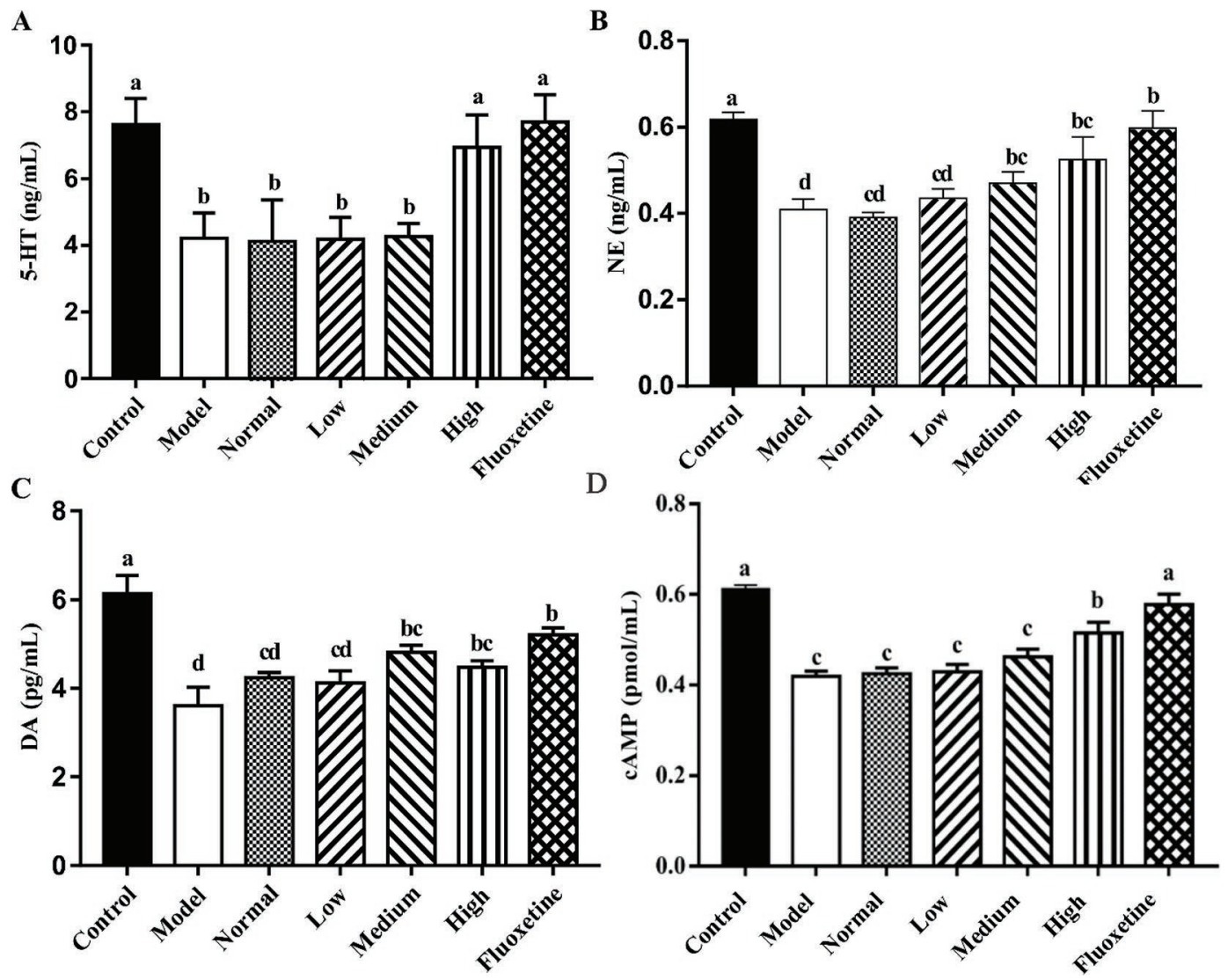

Figure 5. Quantification of monoamines in mice hippocampus measured by ELISA. The concentrations of 5-hydroxytryptamine (5-HT; A), norepinephrine (NE; B), dopamine (DA; C) and cyclic AMP (cAMP; D) were measured in differently treated groups. Groups: (1) healthy mice administered $0.4 \mathrm{~mL}$ of saline $(0.9 \% \mathrm{NaCl}$, "control"); (2) mild depression-like mouse model, with mice administered $0.4 \mathrm{~mL}$ of saline $(0.9 \% \mathrm{NaCl}$, "model"); (3) mice administered common fermented milk ["normal," $0.4 \mathrm{~mL}$ of fermented milk without $\gamma$-aminobutyric acid (GABA)]; (4) mice administered a low dose of adzuki bean sprout fermented milk ("low," $0.1 \mathrm{~mL}$ of GABA-enriched fermented milk with $0.3 \mathrm{~mL}$ of saline sample per day); (5) mice administered half dose of adzuki bean sprout fermented milk ("medium," $0.2 \mathrm{~mL}$ of GABA-enriched fermented milk with 0.2 $\mathrm{mL}$ of saline per day); (6) mice administered full dose of adzuki bean sprout fermented milk ("high," 0.4 mL of GABA-enriched fermented milk sample per day); and (7) mice treated with fluoxetine (20 mg/kg of BW per day; "fluoxetine"). Different letters (a-d) indicate significant differences between groups $(P<0.05)$, and error bars indicate the standard deviation (SD). 
that it plays a regulatory role in neurobehavior and emotional regulation, and that altered 5-HT activity in the brain may lead to depression, anxiety, or mania (Chen et al., 2019). The deficiency can be due to abnormal endogenous release and secondary exhaustion caused by chronic systemic stimulation. In this study, the high-dose fermented milk group may have experienced decreased symptoms of depression due to an increase in 5-HT content. Similar trends were found in NE levels. Dopamine is another neurotransmitter, and it is most relevant to the reward mechanism. Studies have found that DA receptor polymorphisms and lack of pleasure in individuals with depression are closely related (Juárez Olguín et al., 2016). Preventing chronic social frustration and depression in mice may be achieved to some extent by increasing DA content.

There are 3 types of GABA receptors: $\mathrm{GABA}_{\mathrm{A}}$, GAB$A_{B}$, and $G_{A B A}$. The $B$ receptor is a $G$ protein-coupled transmembrane-type metabolic receptor, which is distributed on the presynaptic and posterior membranes (Hirano, 2016). Activation of the $\mathrm{GABA}_{\mathrm{B}}$ receptor causes changes in $\mathrm{K}^{+}$and $\mathrm{Ca}^{+}$channels by regulating neurotransmitter and hormone release, and affects the production of the second messenger cyclic adenylate (cAMP) in the brain (Cunningham and Enna, 1996; Nikoui et al., 2016). The cAMP signaling pathway was one of the earliest studied and it has been researched the most thoroughly in relation to the pathogenesis
A

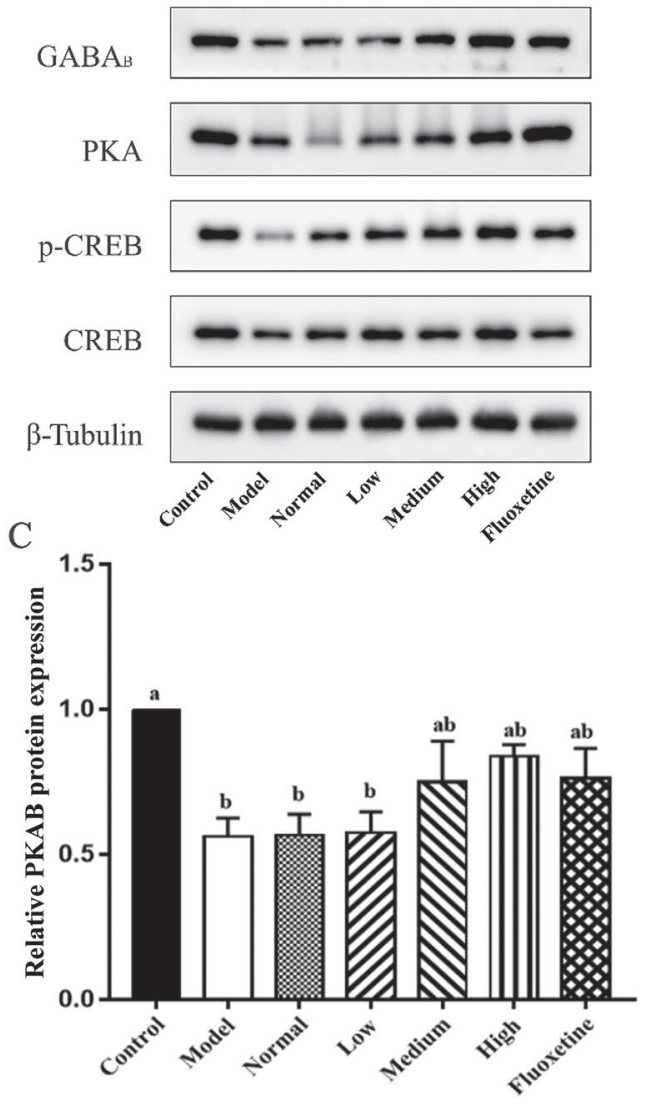

B
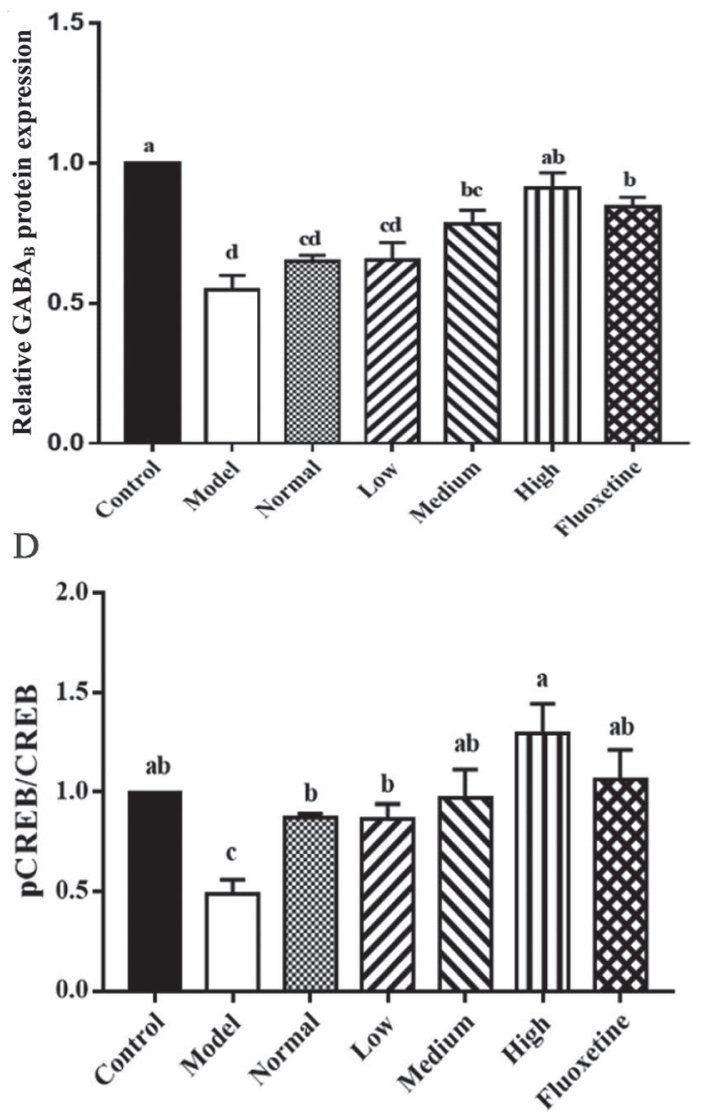

Figure 6. Western blot analysis of the proteins related to the $\gamma$-aminobutyric acid (GABA) B receptor-cAMP-protein kinase A-cAMPresponse element binding protein $\left(\mathrm{GABA}_{\mathrm{B}}-\mathrm{cAMP}-\mathrm{PKA}-\mathrm{CREB}\right)$ signaling pathway in mice hippocampus when treated with GABA-enriched fermented milk. (A) GABA , PKA, CREB, and phosphorylated (p)-CREB protein expression levels in mice hippocampus. Quantification of the expression of $\mathrm{GABA}_{\mathrm{B}}(\mathrm{B})$, PKA (C), and p-CREB/CREB ratio (D) protein in the mouse hippocampus using Image-Pro Plus software (Media Cybernetics, Rockville, MD). Groups: (1) healthy mice administered $0.4 \mathrm{~mL}$ of saline ( $0.9 \% \mathrm{NaCl}$, "control"); (2) mild depression-like mouse model, with mice administered $0.4 \mathrm{~mL}$ of saline $(0.9 \% \mathrm{NaCl}$, "model"); (3) mice administered common fermented milk ("normal," $0.4 \mathrm{~mL}$ of fermented milk without GABA); (4) mice administered a low dose of adzuki bean sprout fermented milk ("low," $0.1 \mathrm{~mL}$ of GABA-enriched fermented milk with $0.3 \mathrm{~mL}$ of saline per day); (5) mice administered half dose of adzuki bean sprout fermented milk ("medium," $0.2 \mathrm{~mL}$ of GABAenriched fermented milk with $0.2 \mathrm{~mL}$ of saline water sample per day); (6) mice administered full dose of adzuki bean sprout fermented milk ("high," $0.4 \mathrm{~mL}$ of GABA-enriched fermented milk sample per day); and (7) mice treated with fluoxetine (20 mg/kg of BW per day; "fluoxetine"). Different letters $(\mathrm{a}-\mathrm{d})$ indicate significant differences between groups $(P<0.05)$, and error bars indicate the standard deviation $(\mathrm{SD})$. 
of depression. The $\mathrm{GABA}_{\mathrm{B}}$ receptor can modulate $\mathrm{p}$ CREB expression in the nucleolus through PKA with a cAMP-dependent signaling pathway. Additionally, as the activator of PKA, cAMP can be translocated into the nuclei along with the catalytic subunit of PKA to phosphorylate CREB, thus regulating neurological functions in the $\mathrm{GABA}_{\mathrm{B}}$-cAMP-PKA-CREB signaling pathway (Lee et al., 2011; Ali Shah et al., 2013). A variety of nervous system functions are regulated by CREB and it plays an important role in the central nervous system (Whitaker and Wei, 2009), although its regulatory transcription function is affected by its own phosphorylation (p-CREB; Saeki et al., 1999). Phosphorylation of CREB can regulate the activity of transcription factors, mediating cell function in the nervous system (Zamarbide et al., 2014). Compared with the model group, mice in the medium- and highdose GABA-enriched adzuki bean sprout fermented milk groups showed significantly increased expression levels of $\mathrm{GABA}_{\mathrm{B}}$, PKA, and p-CREB proteins in the mouse hippocampus, which means that the $\mathrm{GABA}_{\mathrm{B}^{-}}$ cAMP-PKA-CREB signaling pathway was related to the symptoms of depression, and that GABA-enriched adzuki bean sprout fermented milk is a potential dietary approach to preventing mild depression in mice - and potentially in humans.

\section{CONCLUSIONS}

We prepared a functional fermented milk by combining a lactic acid bacterial strain $L b$. brevis $\mathrm{J} 1$ that was shown to have high GABA production and an adzuki bean sprout fermented milk that was also rich in GABA. The obtained fermented milk displayed a significant effect in relieving mild depression-like symptoms in a mouse model. The results of this study suggest that GABA-enriched adzuki bean sprout fermented milk has potential as a new dietary therapy for the adjuvant treatment of chronic social stress.

\section{ACKNOWLEDGMENTS}

This work was supported by the Jiangsu Science and Technology Department (BE2018397), Jiangsu Agricultural Science and Technology Innovation Fund [CX (18)3036], and Natural Science Funding of China (31671869, 32072192, 32072192, and 31972048) and Zhejiang Province (LY19C200005). The authors declare no conflicts of interest.

\section{REFERENCES}

Ali Shah, S., I. Ullah, H. Y. Lee, and M. O. Kim. 2013. Anthocyanins protect against ethanol-induced neuronal apoptosis via GABAB1 receptors intracellular signaling in prenatal rat hippocampal neurons. Mol. Neurobiol. 48:257-269. https://doi.org/10.1007/s12035 $-013-8458-y$.

Alves, T. B., L. T. Totola, A. C. Takakura, E. Colombari, and T. S. Moreira. 2016. GABA mechanisms of the nucleus of the solitary tract regulates the cardiovascular and sympathetic effects of moxonidine. Auton. Neurosci. 194:1-7. https://doi.org/10.1016/j .autneu.2015.11.001.

Anakwenze, U., and D. Zuberi. 2013. Mental health and poverty in the inner city. Health Soc. Work 38:147-157. https://doi.org/10 $.1093 / \mathrm{hsw} / \mathrm{hlt} 013$.

Barrett, E., R. P. Ross, P. W. O'Toole, G. F. Fitzgerald, and C. Stanton. 2012. $\gamma$-Aminobutyric acid production by culturable bacteria from the human intestine. J. Appl. Microbiol. 113:411. https://doi .org/10.1111/j.1365-2672.2012.05344.x.

Berrazaga, I., J. L. Mession, K. Laleg, J. Salles, C. Guillet, V. Patrac, C. Giraudet, O. Le Bacquer, Y. Boirie, V. Micard, F. Husson, R. Saurel, and S. Walrand. 2019. Formulation, process conditions, and biological evaluation of dairy mixed gels containing fava bean and milk proteins: Effect on protein retention in growing young rats. J. Dairy Sci. 102:1066-1082. https://doi.org/10.3168/jds 2018-14610.

Bharwani, A., M. F. Mian, M. G. Surette, J. Bienenstock, and P. Forsythe. 2017. Oral treatment with Lactobacillus rhamnosus attenuates behavioural deficits and immune changes in chronic social stress. BMC Med. 15:7. https://doi.org/10.1186/s12916-016-0771 -7 .

Bunney, W. E. J., and J. M. Davis. 1965. Norepinephrine in depressive reactions. A review. Arch. Gen. Psychiatry 13:483-494. https://doi .org/10.1001/archpsyc.1965.01730060001001.

Chen, B., J. Li, Y. Xie, X. Ming, G. Li, J. Wang, M. Li, X. Li, and L. Xiong. 2019. Cang-ai volatile oil improves depressive-like behaviors and regulates DA and 5-HT metabolism in the brains of CUMSinduced rats. J. Ethnopharmacol. 244:112088. https://doi.org/10 $.1016 /$ j.jep.2019.112088.

Chuang, C. Y., Y. C. Shi, H. P. You, Y. H. Lo, and T. M. Pan. 2011. Antidepressant effect of GABA-rich monascus-fermented product on forced swimming rat model. J. Agric. Food Chem. 59:30273034. https://doi.org/10.1021/jf104239m.

Cunningham, M. D., and S. J. Enna. 1996. Evidence for pharmacologically distinct $\mathrm{GABAB}$ receptors associated with cAMP production in rat brain. Brain Res. 720:220-224. https://doi.org/10.1016/ 0006-8993(96)00120-5.

de los Reyes-Gavilan, C. G., M. Fernandez, J. A. Hudson, and R. Korpela. 2015. Role of microorganisms present in dairy fermented products in health and disease. BioMed Res. Int. 2015:204173. https://doi.org/10.1155/2015/204173.

Diana, M., J. Quílez, and M. Rafecas. 2014. Gamma-aminobutyric acid as a bioactive compound in foods: A review. J. Funct. Foods 10:407-420. https://doi.org/10.1016/j.jff.2014.07.004.

Fayed, A. E. 2015. Review article: Health benefits of some physiologically active ingredients and their suitability as yoghurt fortifiers. J. Food Sci. Technol. 52:2512-2521. https://doi.org/10.1007/s13197 -014-1393-8.

Felton, E. A., and M. C. Cervenka. 2015. Dietary therapy is the best option for refractory nonsurgical epilepsy. Epilepsia 56:1325-1329. https://doi.org/10.1111/epi.13075.

Gahruie, H. H., M. H. Eskandari, G. Mesbahi, and M. A. Hanifpour. 2015. Scientific and technical aspects of yogurt fortification: A review. Food Sci. Hum. Wellness 4:1-8. https://doi.org/10.1016/j fshw.2015.03.002.

He, J. Y., W. W. Wang, Z. Wu, D. D. Pan, Y. X. Guo, Z. D. Cai, and L. W. Lian. 2019. Effect of Lactobacillus reuteri on intestinal microbiota and immune parameters: Involvement of sex differences. J. Funct. Foods 53:36-43. https://doi.org/10.1016/j.jff .2018.12.010.

Hirano, T. 2016. GABA Pathways and Receptors. Pages 225-229 in Essentials of Cerebellum and Cerebellar Disorders. D. L. Gruol, N. Koibuchi, M. Manto, M. Molinari, J. D. Schmahmann, and Y. Shen, ed. Springer, Cham, Switzerland. 
Janik, R., L. A. M. Thomason, A. M. Stanisz, P. Forsythe, J. Bienenstock, and G. J. Stanisz. 2016. Magnetic resonance spectroscopy reveals oral Lactobacillus promotion of increases in brain GABA, N-acetyl aspartate and glutamate. Neuroimage 125:988-995. https: //doi.org/10.1016/j.neuroimage.2015.11.018.

Jiménez-Colmenero, F. 2013. Potential applications of multiple emulsions in the development of healthy and functional foods. Food Res. Int. 52:64-74. https://doi.org/10.1016/j.foodres.2013.02.040.

Juárez Olguín, H., D. Calderon Guzman, E. Hernandez Garcia, and G. Barragan Mejia. 2016. The role of dopamine and its dysfunction as a consequence of oxidative stress. Oxid. Med. Cell. Longev. 2016:9730467. https://doi.org/10.1155/2016/9730467.

Kaidanovich-Beilin, O., T. Lipina, I. Vukobradovic, J. Roder, and J. R. Woodgett. 2011. Assessment of social interaction behaviors. J. Vis. Exp. 48:2473.

Kanehira, T., Y. Nakamura, K. Nakamura, K. Horie, N. Horie, K. Furugori, Y. Sauchi, and H. Yokogoshi. 2011. Relieving occupational fatigue by consumption of a beverage containing gamma-amino butyric acid. J. Nutr. Sci. Vitaminol. (Tokyo) 57:9-15. https://doi .org/10.3177/jnsv.57.9.

Komatsuzaki, N., J. Shima, S. Kawamoto, H. Momose, and T. Kimura. 2005. Production of $\gamma$-aminobutyric acid (GABA) by Lactobacillus paracasei isolated from traditional fermented foods. Food Microbiol. 22:497-504. https://doi.org/10.1016/j.fm.2005.01.002.

Lee, B.-J., J.-S. Kim, Y. M. Kang, J.-H. Lim, Y.-M. Kim, M.-S. Lee, M.-H. Jeong, C.-B. Ahn, and J.-Y. Je. 2010. Antioxidant activity and $\gamma$-aminobutyric acid (GABA) content in sea tangle fermented by Lactobacillus brevis BJ20 isolated from traditional fermented foods. Food Chem. 122:271-276. https://doi.org/10.1016/ j.foodchem.2010.02.071.

Lee, H. Y., B. C. Yang, E. S. Lee, J. I. Chung, P. O. Koh, M. S. Park, and M. O. Kim. 2011. Modulation by the GABAB receptor siRNA of ethanol-mediated PKA- $\alpha$, CaMKII, and p-CREB intracellular signaling in prenatal rat hippocampal neurons. Anat. Cell Biol. 44:210-217. https://doi.org/10.5115/acb.2011.44.3.210.

Li, H., T. Qiu, Y. Cao, J. Yang, and Z. Huang. 2009. Pre-staining paper chromatography method for quantification of gamma-aminobutyric acid. J. Chromatogr. A 1216:5057-5060. https://doi.org/ 10.1016/j.chroma.2009.04.044.

Li, L. M., B. J. Liu, and X. L. Zheng. 2011. Bioactive ingredients in adzuki bean sprouts. J. Med. Plants Res. 5:5894-5898.

Lin, Y. T., C. C. Pao, S. T. Wu, and C. Y. Chang. 2015. Effect of different germination conditions on antioxidative properties and bioactive compounds of germinated brown rice. BioMed Res. Int. 2015:608761. https://doi.org/10.1155/2015/608761.

Liu, W., H. Wang, Y. Wang, H. Li, and L. Ji. 2015. Metabolic factorstriggered inflammatory response drives antidepressant effects of exercise in CUMS rats. Psychiatry Res. 228:257-264. https://doi .org/10.1016/j.psychres.2015.05.102.

Ma, K., A. Xu, S. Cui, M. R. Sun, Y. C. Xue, and J. H. Wang. 2016. Impaired GABA synthesis, uptake and release are associated with depression-like behaviors induced by chronic mild stress. Transl. Psychiatry 6:e910. https://doi.org/10.1038/tp.2016.181.

Madhu, A. N., N. Amrutha, and S. G. Prapulla. 2012. Characterization and antioxidant property of probiotic and synbiotic yogurts. Probiotics Antimicrob. Proteins 4:90-97. https://doi.org/10.1007/ s12602-012-9099-6.

Mazzarella, G., A. Perna, A. Marano, A. Lucariello, V. Rotondi Aufiero, A. Sorrentino, R. Melina, G. Guerra, F. S. Taccone, G. Iaquinto, and A. De Luca. 2017. Pathogenic role of associated adherent-invasive Escherichia coli in Crohn's disease. J. Cell. Physiol. 232:2860-2868. https://doi.org/10.1002/jcp.25717.

Minervini, F., M. T. Bilancia, S. Siragusa, M. Gobbetti, and F. Caponio. 2009. Fermented goats' milk produced with selected multiple starters as a potentially functional food. Food Microbiol. 26:559-564. https://doi.org/10.1016/j.fm.2009.03.008.

Nardone, G., and D. Compare. 2015. The human gastric microbiota: Is it time to rethink the pathogenesis of stomach diseases? United European Gastroenterol. J. 3:255-260. https://doi.org/10.1177/ 2050640614566846.
Nikoui, V., S. Ostadhadi, P. Azhand, S. Zolfaghari, S. Amiri, M. Foroohandeh. M. Motevalian, A. M. Sharifi, and A. Bakhtiarian. 2016. The effect of nitrazepam on depression and curiosity in behavioral tests in mice: The role of potassium channels. Eur. J. Pharmacol. 791:369-376. https://doi.org/10.1016/j.ejphar.2016.09.017.

Okada, T., T. Sugishita, T. Murakami, H. Murai, T. Saikusa, T. Horino, A. Onoda, O. Kajimoto, R. Takahashi, and T. Takahashi. 2000. Effect of the defatted rice germ enriched with GABA for sleeplessness, depression, autonomic disorder by oral administration. Nippon Shokuhin Kagaku Kogaku Kaishi 47:596-603. https: //doi.org/10.3136/nskkk.47.596.

Oliveira, L. C., D. C. N. Lima, M. A. Bailoni, E. M. Risso, M. Schmiele, C. J. Steel, and Y. K. Chang. 2017. Physical characteristics, nutritional quality, and antioxidant potential of extrudates produced with polished rice and whole red bean flours. Cereal Chem. 94:74-81. https://doi.org/10.1094/CCHEM-05-16-0129-FI.

Patterson, E., P. M. Ryan, N. Wiley, I. Carafa, E. Sherwin, G. Moloney, E. Franciosi, R. Mandal, D. S. Wishart, K. Tuohy, R. P. Ross, J. F. Cryan, T. G. Dinan, and C. Stanton. 2019. Gammaaminobutyric acid-producing lactobacilli positively affect metabolism and depressive-like behaviour in a mouse model of metabolic syndrome. Sci. Rep. 9:16323. https://doi.org/10.1038/s41598-019 $-51781-x$.

Petty, F. 1995. GABA and mood disorders: A brief review and hypothesis. J. Affect. Disord. 34:275-281. https://doi.org/10.1016/ 0165-0327(95)00025-I.

Ribeiro, S. C., M. F. P. Domingos-Lopes, C. Stanton, R. P. Ross, and C. C. G. Silva. 2018. Production of $\gamma$-aminobutyric acid (GABA) by Lactobacillus otakiensis and other Lactobacillus sp. isolated from traditional Pico cheese. Int. J. Dairy Technol. 71:1012-1017. https://doi.org/10.1111/1471-0307.12527.

Saeki, K., A. Yuo, and F. Takaku. 1999. Cell-cycle-regulated phosphorylation of cAMP response element-binding protein: Identification of novel phosphorylation sites. Biochem. J. 338:49-54. https://doi .org/10.1042/bj3380049.

Sharifi Yazdi, M. K., A. Davoodabadi, H. R. Khesht Zarin, M. Tajabadi Ebrahimi, and M. M. Soltan Dallal. 2017. Characterisation and probiotic potential of lactic acid bacteria isolated from Iranian traditional yogurts. Ital. J. Anim. Sci. 16:185-188. https://doi.org/10 $.1080 / 1828051$ X.2016.1222888.

Sharma, S., and S. S. Kanwar. 2017. Adherence potential of indigenous lactic acid bacterial isolates obtained from fermented foods of Western Himalayas to intestinal epithelial Caco-2 and HT-29 cell lines. . Food Sci. Technol. 54:3504-3511. https://doi.org/10 $.1007 / \mathrm{s} 13197-017-2807-1$.

Shi, H., P. K. Nam, and Y. Ma. 2010. Comprehensive profiling of isoflavones, phytosterols, tocopherols, minerals, crude protein, lipid, and sugar during soybean (Glycine max) germination. J. Agric. Food Chem. 58:4970-4976. https://doi.org/10.1021/jf100335j.

Smith, K. L., J. I. Cunningham, D. J. Eyerman, R. L. Dean 3rd, D. R. Deaver, and C. Sanchez. 2019. Opioid system modulators buprenorphine and samidorphan alter behavior and extracellular neurotransmitter concentrations in the Wistar Kyoto rat. Neuropharmacology 146:316-326. https://doi.org/10.1016/j.neuropharm .2018.11.015.

Sodini, I., J. Montella, and P. S. Tong. 2005. Physical properties of yogurt fortified with various commercial whey protein concentrates. J. Sci. Food Agric. 85:853-859. https://doi.org/10.1002/jsfa.2037.

Su, W. J., W. Peng, H. Gong, Y. Z. Liu, Y. Zhang, Y. J. Lian, Z. Y. Cao, R. Wu, L. L. Liu, B. Wang, Y. X. Wang, and C. L. Jiang. 2017. Antidiabetic drug glyburide modulates depressive-like behavior comorbid with insulin resistance. J. Neuroinflamm. 14:210. https://doi.org/10.1186/s12974-017-0985-4.

Vaiva, G., P. Thomas, F. Ducrocq, M. Fontaine, V. Boss, P. Devos, C. Rascle, O. Cottencin, A. Brunet, P. Laffargue, and M. Goudemand. 2004. Low posttrauma GABA plasma levels as a predictive factor in the development of acute posttraumatic stress disorder. Biol. Psychiatry 55:250-254. https://doi.org/10.1016/j.biopsych .2003.08.009. 
Weir, G. C., and S. Bonner-Weir. 2017. GABA signaling stimulates beta cell regeneration in diabetic mice. Cell 168:7-9. https://doi .org/10.1016/j.cell.2016.12.006.

Whitaker, C. M., and H. Wei. 2009. An alternate cAMP pathway Epac promotes hippocampal long-term depression. J. Physiol. 587:30673068. https://doi.org/10.1113/.jphysiol.2009.175216.

Wu, C. H., Y. H. Hsueh, J. M. Kuo, and S. J. Liu. 2018. Characterization of a potential probiotic Lactobacillus brevis RK03 and efficient production of $\gamma$-aminobutyric acid in batch fermentation. Int. J. Mol. Sci. 19:143. https://doi.org/10.3390/ijms19010143.

Xu, Y., H. Sheng, Q. Bao, Y. Wang, J. Lu, and X. Ni. 2016. NLRP3 inflammasome activation mediates estrogen deficiency-induced depression- and anxiety-like behavior and hippocampal inflammation in mice. Brain Behav. Immun. 56:175-186. https://doi.org/10 .1016/j.bbi.2016.02.022.

Yi, L. T., Y. C. Li, Y. Pan, J. M. Li, Q. Xu, S. F. Mo, C. F. Qiao, F. X. Jiang, H. X. Xu, X. B. Lu, L. D. Kong, and H. F. Kung. 2008. Antidepressant-like effects of psoralidin isolated from the seeds of
Psoralea Corylifolia in the forced swimming test in mice. Prog. Neuropsychopharmacol. Biol. Psychiatry 32:510-519. https://doi .org/10.1016/j.pnpbp.2007.10.005.

Zamarbide, M., I. Etayo-Labiano, A. Ricobaraza, E. Martinez-Pinilla, M. S. Aymerich, J. Luis Lanciego, A. Perez-Mediavilla, and R. Franco. 2014. GPR40 activation leads to CREB and ERK phosphorylation in primary cultures of neurons from the mouse CNS and in human neuroblastoma cells. Hippocampus 24:733-739. https://doi.org/10.1002/hipo.22263.

\section{ORCIDS}

Zhen Wu ( https://orcid.org/0000-0002-3607-6440

Pengyu Wang () https://orcid.org/0000-0002-8017-3045

Daodong Pan ๑ https://orcid.org/0000-0002-5299-644X

Yuxing Guo @ https://orcid.org/0000-0003-2935-9781 